\title{
Teaching Innovation of Physical Education Curriculum in Colleges and Universities in the Environment of "Sunshine Sports"
}

\author{
Chen wei guo \\ (Hainan vocational and technical college, Hainan, Haikou 570216)
}

Keywords: colleges and universities; Physical Education Teaching; Sunshine Sports

\begin{abstract}
The "Sunshine Sports" of hundreds of millions of students nationwide is an important measure to improve the health of young people. In this context, the teaching of physical education in Colleges and universities must be innovate. Only in this way can it adapt to the high-quality needs of the students at all levels, and ultimately enhance the overall level of physical health of college students.
\end{abstract}

\section{Introduction}

The "Sunshine Sports" put forward by the Ministry of education makes the teaching of physical education in colleges and universities face new challenges. In the implementation of the "Sunshine Sports" in some schools, there is a lack of a more profound understanding, so there are some problems in sports hours. National physical fitness monitoring data shows that some physical fitness indicators of effective students are decreasing. Overweight, poor physical quality, poor eyesight and other problems are more common. To some extent, they restrict college students to enter the social [1]. The implementation of "Sunshine Sports" in physical education teaching in colleges and universities is conducive to encouraging students to form good habits of physical exercise. It is an inevitable requirement for the innovation of physical education curriculum in colleges and universities.

\section{An overview of "Sunshine Sports"}

The "Decision of carrying out the sports in hundreds of millions of students throughout the country published by the Ministry of Education, the General Administration of Sport and the Central Committee of the Communist Youth League" has clearly pointed out the necessity of carrying out the sunshine sports. Zhou Hongyu's theory of "sunshine education" was the first time to put forward the idea of "Sunshine Sports". He believes that sunshine education is that teachers should make their students be fierce, care and love through love, and at the same time, they should gradually develop a sense of teamwork and a spirit of cooperation to work hard to make progress [2]. This new idea is a challenge to the traditional relationship between teachers and students. It adapts to the student-centered teaching concept and takes the relationship between students and students and the relationship between teachers and students to a new height. Sunshine education is a kind of utilitarian education, which belongs to a multidimensional interactive and influential practice process. It has the characteristics of openness, integrity and student-centered. Openness refers to the fact that sports are not traditional education. Students will take various forms of exercise after obtaining a certain theoretical knowledge, so that the emotional communication between teachers and students and students can be improved. Students also no longer need to accept a long period of theoretical instillation and learning methods have been enriched. Students can study in a wide track and field places, such as mountains and rivers. The selection of teachers' teaching places can be based on the actual needs of the teaching projects, and the selection of students' participation in the community can be based on their own interests and hobbies. While, integrity means paying attention to the students 'health while paying attention to providing a 
learning environment conducive to self-improvement to students so that the students' WQ , EQ and IQ can be developed together. Under the environment of sunshine sports, colleges and universities should pay more attention to enhancing students' WQ and EQ, which ultimately enable students to enhance their WQ ability, such as emotional experience, interpersonal relationship and individual will. Taking students as the center means that teachers should give students' understanding and trust in their life and study, and respect their psychological feelings and emotional appeals.

\section{Innovative Tactics of PE Teaching in Colleges and Universities in the Environment of "Sunshine Sports"}

\section{Creating a multilevel curriculum model}

In the process of physical education teaching in colleges and universities, it is necessary to create a multilevel curriculum model in the face of students' individual differences and the regularities of curriculum setting. That is, according to the grade, level, stage and the different needs of students to create the curriculum, and ultimately making sports developed and improved in popularity and competition. In this regard, colleges and universities should establish a distinctive and diverse contents of physical education curriculum mode with basic, improve and health care, electives and compulsory levels and so on under the premise of respecting the scientific, systematic and basic, so that students can choose sports projects suitable for the needs of their own development according to their own interests and the physiological conditions. For example, the students with relatively poor physical quality can choose sports with lower physical quality, so as to improve their physical quality. Sports specialty students can choose special sports training. It is worth noting that when students choose sports according to their own standards, teachers should give proper guidance and classify them according to their characteristics and learning rules, so as to further set up course listing, teaching time and progress. It is an essential requirement under the environment of "sunshine sports" to create a curriculum system of various forms and levels in PE teaching in colleges and universities, which is compatible with the student-centered teaching idea.

\section{Using modern teaching technology to improve the level of physical education in schools}

In the traditional teaching of physical education in Colleges and universities, a lot of physical education teachers only pass on the abstract sports knowledge to the students through oral and written words. Even some PE teachers use some patterns and models in teaching process to help students enhance their understanding of sports knowledge, the quality and achievement of physical education in colleges and universities is still not satisfactory. And it will waste a lot of time and energy on the teaching of college students, and the teaching is inefficient. With the development of society, all kinds of modern technology are more and more widely used in the teaching process. Physical education and modern teaching techniques can be combined in the physical education of college students. For example, physical education teachers can use multimedia, three-dimensional space to explain the emphasis and difficulties in physical education, so that students can learn more abstract sports knowledge, improve learning efficiency and teaching quality. For example, before explaining the roll motion to the students, the teacher can make use of the multimedia to replay and slowdown the action essentials, so that the students can recognize the causes and specific countermeasures of the common mistakes in the action essentials. Using this intuitive and easy way to help students master the essentials of exercise and gain a better experience in the classroom.

Colleges and universities have a lot of physical education for students, such as volleyball, gymnastics, basketball, gymnastics, tennis, martial arts, swimming and so on. With the increase of teaching programs, the teaching materials, educational contents and teaching concepts for these projects are constantly updated, which poses a great challenge to the teaching level of college PE teachers. China's Ministry of Education made it clear that colleges and universities not only impart professional sports knowledge and skills to students during their physical education, but also emphasize to pass the sports spirit to the students so that they can set up the idea of lifelong exercise, more consciously to exercise and learning. In order to do a good job in physical education, teachers must be able to give students a correct standard demonstration and set up correct technical ideas for the students. However, some PE teachers' lack of personal accomplishment and professional 
knowledge makes the existing education goal impossible. Using modern teaching techniques can effectively help teachers solve this problem. Through the application of modern education technology in physical education, it is able to play the advanced technology of world elite athletes directly to students, helping students learn the correct complete movement, advanced and perfect sports knowledge and skills, and meet the teaching idea of "Sunshine Sports" in colleges and universities.

At present, many colleges and universities have put forward the goal of building a modern teaching management mode. Almost every school in our country regularly holds school games every year, which brings a lot of workload to school PE teachers. The application of modern educational technology in physical education can enable physical education teachers to use computers to arrange sports events and greatly reduce the workload of physical education teachers. Teachers can prepare a school physical education system, which includes teacher preparation management, student physical education standards, physical fitness management, sports performance management, sports team management, etc. Physical education teachers can manage the physical education and sports events through the network. For example, the physical education scores can be queried by students. It is only necessary for students to input their personal performance and their corresponding scores, whether the total score can reach the standard, and the average score can be displayed intuitively. This type of model can also be used in other aspects of the school, greatly promoting the modern teaching management model.

\section{Mining a variety of curriculum resources}

Under the environment of "Sunshine Sports", physical education curriculum in colleges and universities needs to excavate physical education curriculum resources to enrich the forms and contents of physical education courses, and enhance its role in culture, society, health and entertainment. The universal, lifelong and educational nature of sports is the ultimate goal of developing "Sunshine Sports". At the same time, sports in colleges and universities can be adjusted by athletics as a pattern of teaching materials and activities [3]. Therefore, universities need to rely on natural resources, family and social resources to effectively excavate curriculum resources and enrich the form and content of "Sunshine Sports". Specifically, colleges and universities should promote competitive sports teaching materials, by reducing the load of exercise, reducing the technical difficulty, the appropriate adjustment of the requirements of sports venues, changing the basic rules of competition. Making the complex and difficult competitive sports adapted to the actual needs of college students, at the same time getting the students' favorite in the shortest time. Colleges and universities should continue to introduce ethnic sports with humanities heritage, making it suitable for the development needs of students sports style. We can make full use of the national rich cultural resources to effectively improve the traditional sports so that it is compatible with the current trend of sports development and meet the general psychological needs of the general public. Meanwhile, the national sports programs will also be effectively promoted. Colleges and universities should make full use of the leisure life style adapted to the needs of the people and excavate the outdoor sports effectively. Relying on social and natural resources, so that the general public, the times, fitness and sports programs fully integrated into college PE teaching.

\section{Establishing a system of lifelong physical education}

To enhance the physical quality of university students is the fundamental requirement of college physical education, but in this process, we must uphold the idea of lifelong education and lifelong physical education. Although "Sunshine Sports" is to enable students to develop their physical education by the reason of political theory, the real purpose is to increase the physical training time for college students and to form a good habit of physical exercise so as to finally improve their physical fitness and physical education for lifelong awareness is established. Physical education curriculum in Colleges and universities is designed to meet the needs of students' physical and mental development as well as student centered educational philosophy, so as to enhance students' professional skills and basic sports skills related to future careers. Therefore, in the process of college physical education curriculum reform, we should pay attention to guiding the students to form the awareness of lifelong physical education and comprehensively enhance the physical 
quality of the students in order to meet the needs of a highly competitive social life, to enable students to adapt to the fast-paced social life earlier and to enhance their own handling problems such as occupational viability.

\section{Standardization of sports ideas}

In the environment of "Sunshine Sports", colleges and universities need to create a relatively complete curriculum system which integrates competition, training and teaching. At the same time, we should integrate outdoor and extracurricular sports competitions into the curriculum teaching system, so as to ensure the development of college sports activities with system guarantee and theoretical support. In this way, outdoor sports activities, which have been excluded from other courses for a long time, will be greatly improved. Colorful sports activities held by schools will attract more and more students to participate. Thus, the institutionalization of movement concept can make sports achieve the purpose of enhancing the physical quality of the students.

\section{Attention to the innovation of college physical education under the environment of "Sunshine Sports"}

Under the environment of "sunshine sports", the content of education and the relationship between teachers and students have been innovated, which effectively make up for the shortage of teaching of traditional physical education, but some places still need to be noticed in the concrete implementation. For example, we should pay attention to the practical value of the curriculum.Under the influence of the western economic sports curriculum theory, the disadvantages of the college physical education curriculum are becoming more and more apparent. For example, the actual effectiveness is not enough, if we ask non sports majors to achieve a higher success in track and field and other projects is of no great value, students are more likely to relax through physical exercise, so the innovation of physical education curriculum in colleges and universities should pay attention to practicality. Because "Sunshine Sports" advocates an outdoor sport, we should play its role in enriching the lifestyle and so on, and carry out outdoor activities such as hiking, camping and mud crossing. In addition, the proportion of elective and compulsory courses should also be properly allocated.

\section{Conclusion}

Under the environment of "Sunshine Sports", the teaching methods of physical education in colleges and universities show more respect to the students' main position. The implementation of optional elective of education form for teachers and students has payed more attention to students' personality. They have set a relatively complete course type, payed attention to innovation in teaching methods and used diverse teaching methods. However, in this process, the teaching team, the teaching evaluation, the teaching resources and the quality of teaching are faced with a certain predicament. However, only by implementing effective innovation strategies can colleges and universities truly realize the further development of the teaching of physical education.

\section{Reference}

[1]Ma Jinfeng. Teaching Reform of Innovative Courses of Physical Education in Colleges and Universities under the Background of "Sunshine Sports"[J]. Sports World: Academic Edition, 2010,11:25-26.

[2]Zhou Wenbo. Innovation and Reform of College Physical Education Theory Course under the View of "Sunshine Sports"[J]. Journal of Hubei Water Resources Technical College, 2014,6:90-90.

[3]Yu Kuilong,Wu Changweng. Reflections on the Teaching Reform of Public Physical Education in Colleges and Universities from the Perspective of "Sunshine Sports"[J]. Journal of Lanzhou University of Arts and Sciences (Natural Science Edition), 2010, 3:115-118. 